\title{
Immunological Parameters Examination of the Oral Fluid in Normal and Pathological Conditions: Sensitivity Analysis of Microorganisms in Modern Therapeutic practice in vitro
}

\author{
Abdulrazaq Mohammad SABAH ${ }^{1}$, Ikonnikova NATALIYA ${ }^{2}$ \\ ${ }^{1}$ International Sakarov Enviromental Institute of Belarusian State University, Minsk, Belarus \\ *Corresponding Author Email : mohmmedaldraje4@ gmail.com ORCID: 0000-0003-1737-2874 \\ ${ }^{2}$ International Sakarov Enviromental Institute of Belarusian State University,Minsk, Belarus \\ Email: i.nataliya@gmail.com - ORCID: 0000-0002-1733-1832
}

\section{Article Info:}

DOI: $10.22399 /$ ijcesen. 1011762

Received : 18 October 2021

Accepted : 07 November 2021

\section{Keywords}

Mucosal Immune

Oral fluid

Immunological

\begin{abstract}
$\underline{\text { Abstract: }}$
Inflammation of the mucosal immune system is a common occurrence (saliva). The masticatory process and salivary enzymes destroy antigenic material that enters the mouth cavity, yet it can still activate immunological responses. Many soluble components are secreted by epithelial cells or incorporated into oral cavity fluids. Defensins, histatins, lysozyme, and lactoferrin all have antibacterial action. They appear to work synergistically with secretory IgA. The objectives of this study is to examine the immunological parameters (concentration of total $\operatorname{IgA}$ and secretory $\operatorname{IgA}$ ) of the oral fluid of the examined individuals in normal and pathological conditions; and to identify the sensitivity/resistance of microorganisms-the main representatives of the oral microflora to antimicrobial drugs widely used in modern therapeutic practice (antibiotics) in vitro. To measure secretory $\operatorname{IgA}$ in oral fluid, we used a solid-phase immunoassay and a ZAO Vector Best sIgA ELISA BEST strip. The "secretory IgAELISA" reagent collection is designed to quantify secretory $\operatorname{IgA}$ in body fluids using enzyme-linked immunosorbent assay. The enzyme-linked immunosorbent assay measures secretory IgA. The t-test was used to assess the significance of differences across indicator groups. Results indicated that amount of total $\operatorname{IgA}$ in oral fluid is significantly lower in people with dental and periodontal problems than in people who are healthy. This indicates a decrease in oral cavity resistance and an increase in carious/periodontal processes. Caries and/or periodontal disease have been linked to $\lg$ A deficiency. The results showed that staphylococci and streptococci dominated the oral cavity microbiota in the comparison groups. In addition to this, Neisseria and Veillonella were found. Streptococci accounted for 57 percent of all microorganisms planted in this biotope. Enterobacteria accounted for up to $15 \%$, whereas Neisseria accounted for about $4 \%$ and $2 \%$. The decrease in sIgA levels in periodontitis patients' saliva indicates a lack of local mucous membrane protection, increasing the risk of caries and periodontitis. The lower sIgA levels in the mouth make tooth tissue more susceptible to caries-causing microbe adherence than in healthy people.
\end{abstract}

\section{Introduction}

The mucosal immune system is permeable to external stimuli and is constantly bathed in fluid (saliva). Although antigenic material that enters the oral cavity is largely degraded by the masticatory process and salivary enzymes, it has the potential to elicit immunological responses. And early research into the development of vaccines against tooth cavities demonstrated that Strep. mutans induced
IgA antibodies not only in saliva, but also in tears. This established the notion of a single mucosal immune system, in which the stimulation of immune responses on one mucosal surface resulted in a widespread immunological response in other mucosal tissues $[1,2]$. Inflammation is a protective response that aims to clear the body of invading germs that cause tissue harm, as well as to deal with the resulting necrosis. Cytokines such as interleukin1 (IL-1), interleukin-6 (IL-6), and tumor necrosis 
factor (TNF) drive and regulate the inflammatory process. Inflamed tissues draw phagocytic cells such as neutrophils and macrophages (as well as mast cells and eosinophils) to eliminate invading pathogens. Leucocytes can migrate quickly to infection or tissue injury locations, whereas plasma proteins can diffuse into tissues $[3,4]$.

Numerous soluble factors are released by epithelial cells or incorporated into the fluids that surround the oral cavity. These factors perform a number of roles, including antibacterial activity for defensins, histatins, lysozyme, and lactoferrin. Certain of these compounds have been shown to interact synergistically with secretory $\operatorname{IgA}[5,6]$.

Symbiosis between the human body and its microbial ecological system is the norm and form of life. It is generated during the processes of evolutionary (phylogenesis) and individual (ontogenesis) development. Microorganisms inhabit the human body in numbers tens to hundreds of times greater than the host's own cells [7 -9]. In essence, man (along with higher animals) has evolved into a superorganizational symbiotic system. Along with the macroorganism, the latter consists of a collection of numerous microbiocenoses with a specific composition that inhabit a particular biotope (niche) within the host body. The microbiome is a collection of human microorganisms that cohabit normally and pathologically with it, taking part in physiological and pathophysiological processes, as well as drug and hormone metabolism [10, 11].

It may be concluded that one of the most promising fields of medical research is the investigation of a group of genes involved in the creation of microbiota in diverse localizations, including the gastrointestinal tract, skin, and mucous membranes of the sexual organs. Thus, this study aims to determine immunological parameters (total IgA and secretory $\operatorname{IgA}$ concentrations) in the oral fluid of examined individuals under normal and pathological conditions. to determine the sensitivity/resistance of microorganisms - the primary representatives of the oral microflora - to antimicrobial drugs commonly used in modern therapeutic practice (antibiotics) in vitro.

\section{Methodology}

To carry out the study's objectives, 65 people of various ages (ranging from 18 to 50 years old) were examined, including students, teachers, laboratory assistants, employees of Belarusian State University's International Sakharov Environmental Institute, and patients of the Slutsk district hospital who gave written informed consent to the collection of biological material. A questionnaire survey was undertaken among those polled in order to identify people who had a susceptibility to colds or chronic diseases, poor habits (smoking), and whether or not they practiced regular dental hygiene. Group 1 consisted of 37 persons between the ages of 18 and 25 , whereas group 2 consisted of 28 people between the ages of 43 and 50 . The existence of various oral disorders was discovered in 15 participants, according to the results of the survey. The remaining respondents did not have any oral illnesses (Table $1)$.

Table 1. Group of people who took part in the study

\begin{tabular}{|l|l|l|}
\hline Group number & Group 1 & Group 2 \\
\hline Age & $\begin{array}{l}18-25 \text { years } \\
(\mathrm{n}=37)\end{array}$ & $\begin{array}{l}43-50 \\
\text { years }(\mathrm{n}=28)\end{array}$ \\
\hline $\begin{array}{l}\text { Diseases of the } \\
\text { oral cavity }\end{array}$ & Present $(\mathrm{n}=15)$ & $\begin{array}{l}\text { Absent } \\
(\mathrm{n}=50)\end{array}$ \\
\hline
\end{tabular}

The oral cavity (inside surface of the cheeks) was swabbed and inoculated onto agar media (MPA, Endo medium) using sterile cotton swabs. The quantitative count of microorganisms was accomplished by counting colonies (CFU) on the agar medium's surface and then converting to a specific unit of the oral cavity's area $\left(4 \mathrm{~cm}^{2}\right)$.

We employed a solid-phase immunoassay and a sIgA ELISA BEST strip acquired from ZAO Vector Best to quantify secretory $\operatorname{IgA}$ in oral fluid. Photometric measurements at a wavelength of 450 $\mathrm{nm}$ were used to obtain the analysis results. Blood serum is used as the test material. 100L of material is required for analysis.

The "secretory IgA-ELISA" collection of reagents is intended for the quantitative determination of secretory $\operatorname{IgA}$ in bodily fluids using the enzymelinked immunosorbent assay method. Secretory IgA is quantified using a "sandwich" form of the enzyme-linked immunosorbent test. On the inner surface of the plate wells, mouse monoclonal antibodies specific for secretory human $\operatorname{IgA}$ are immobilized. When the test sample is introduced to the wells of the plate, the secretory $\operatorname{IgA}$ in the test sample binds to antibodies on the solid phase. The resultant complex is identified using a horseradish peroxidase-conjugated mouse monoclonal antibody to the alpha chain of IgA. As a result, a plasticencased "sandwich" containing peroxidase is formed. The fluids in the wells are stained following incubation with a tetramethylbenzidine (TMB) substrate solution. The color intensity is related to the secretory $\operatorname{IgA}$ concentration in the test sample. The calibration graph was used to determine the sIgA concentration in the samples.

To begin, a single colony was extracted from a Petri plate using a toothpick or a bacteriological loop and 
transferred to a test tube (eppendorf). The test tubes were then filled halfway with acetonitrile and $70 \%$ formic acid solution, mixed, and the substance was applied in a volume of 1L to the wells of a metal target (chip). Each sample was loaded with 11 of a MALDI-ToF matrix (-cyano-hydroxycinnamic acid in a 50/25 acetonitrile/ trichloroacetic acid, TPA) solution. After crystallization of the samples, the target was placed in the mass analyzer's chamber with the samples. To calibrate the instrument, E. coli strain CCUG 10797 cells were employed. To obtain a single mass spectrum, 100 laser pulses with a frequency of $60 \mathrm{~Hz}$ were employed; the registration range was $1000-20000 \mathrm{~m} / \mathrm{z}$; only positive ions were recorded; and the whole spectrum of each sample was assembled using 100 single shots. Each well of the chip was sampled for a spectrum, which was the sum of six individual spectra (600 laser pulses). The following properties of the mass spectrum were considered while examining the results: the number of peaks, their strength, and the total value of the noise component. For further examination, the resulting spectrums of each strain were exported to the S.A.R.A.M.I.S. TM database. Individual mass spectra in the "Identification" mode were compared to the S.A.R.A.M.I.S. TM database, supplemented by the obtained reference spectra, to determine the species or genus of the examined culture. Correct species identification was achieved with a score of $75 \%$. Positive identification at the genus level is defined as a score of 1.7, while positive identification at the species level is defined as a score of 2.0 or higher.

Statistical methods were used to determine the mean, standard deviation $(\mathrm{M}+\mathrm{SE})$, median, and spread of values, as well as correlation analysis, during data processing. The significance of differences between indicator groups was determined using the Student's t-test. We classified significant differences as those with a $\mathrm{p} 0.05$ value. When performing statistical analysis on the data, a software application was employed by STATISTICA 10.0 .

\section{Results and Discussions}

The values of immunity indicators (IgA, lysozyme, and SIgA) in the oral cavity of participants are shown in Table 2 where $*$ indicates a $\mathrm{p}<0,05$ statistical significance of differences. Individuals with oral illnesses demonstrated a statistically significant decrease in secretory IgA levels when compared to healthy and normal individuals (Figure 1). In dental caries, secretory immunoglobulin $A$ ( $\operatorname{IgA}$ ) in mixed saliva is a critical indication of local oral immunity. A critical aspect of the role of secretory $\operatorname{IgA}$ in the oral cavity's microbial ecology, and particularly in the pathology of the oral cavity, is the effect of these immunoglobulins on the local microflora. The decreased SIgA content in saliva of patients with caries and periodontal illnesses indicates a weakening of the mucous membranes' local defenses, increasing the chance of a carious process and deterioration of periodontal health.

Table 2. The immunity indicators (IgA, lysozyme, and $S I g A)$ in the oral cavity of participants.

\begin{tabular}{|c|c|c|c|}
\hline Indicator & $\begin{array}{l}\text { Group of } \\
\text { relatively } \\
\text { healthy } \\
\text { people ( } \mathrm{n}= \\
50)\end{array}$ & $\begin{array}{l}\text { Group of } \\
\text { people with } \\
\text { caries and } \\
\text { periodontal } \\
\text { diseases } \\
(\mathrm{n}=15)\end{array}$ & $\begin{array}{c}\text { Normal } \\
\text { values }\end{array}$ \\
\hline $\begin{array}{c}\text { of IgA } \\
\text { indicators, } \\
\mathrm{g} / \mathrm{L}\end{array}$ & $\begin{array}{l}1,053 \pm \\
0,002 *\end{array}$ & $\begin{array}{c}0,741 \\
\pm 0,002 *\end{array}$ & $\begin{array}{c}1,20 \pm \\
0,65\end{array}$ \\
\hline $\begin{array}{c}\text { Lysozyme, } \\
\mu \mathrm{g} / \mathrm{ml}\end{array}$ & $44,0 \pm 1,3 *$ & $30,0 \pm 1,12 *$ & $\begin{array}{c}40,0- \\
50,0\end{array}$ \\
\hline SIgA, g/L & $\begin{array}{l}1.80 \pm \\
0.33^{*}\end{array}$ & $0.28 \pm 0.05^{*}$ & 0.7 to 4 \\
\hline
\end{tabular}

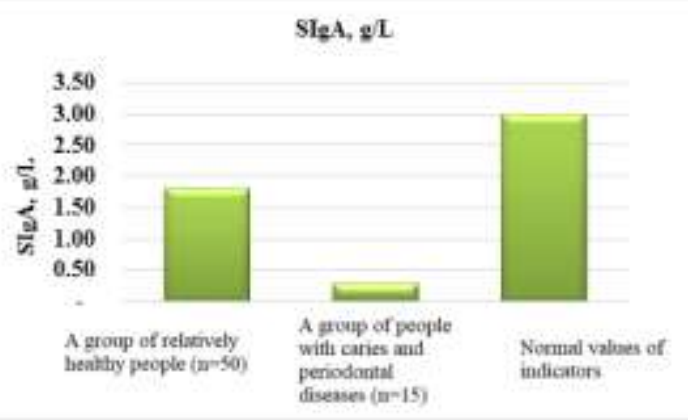

Figure 1: secretory $\operatorname{SIgA,} g / L$ content in the examined individuals

According to the findings obtained, the amount of total IgA in oral fluid is much lower in patients with dental and periodontal problems than in healthy individuals (figure 2). This reflects a decrease in the mouth cavity's specific resistance and the activation of carious/periodontal processes.

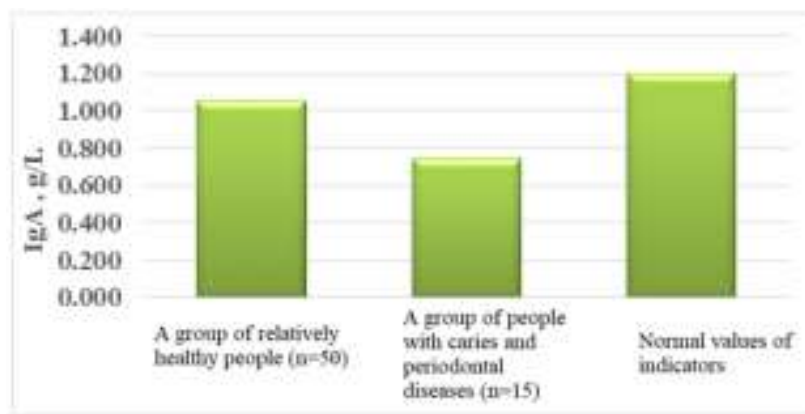

Figure 2: total IgA, g/L Level in the surveyed individuals 
Individuals with $\lg$ A deficiency have been observed to be more prone to tooth decay and/or periodontal disease. Bacteria deglycosylate $\operatorname{IgA}$, which regulates bacteria's adherence to dentin and mucosa, resulting in immunoglobulin proteolysis and a loss in antibacterial defense.

Despite large growth inhibition zones surrounding the anti-biotic disks, all bacteria shown resistance to amoxicillin. Carbenicillin resistance was observed in bacteria belonging to the genera Lactobacillus, Staphylococcus, Bifidobacterium, Escherichia, and Sarcina.

Streptomycin, Doxycycline, and Tetracycline were all susceptible to all microorganisms (Figure 2). According to the boundary data table for the diameter of growth retardation zones (Table 2), all of the bacteria examined are amoxicillin resistant. Lactobacillus, Staphylococcus, Bifidobacterium, Escherichia, and Sarcina are carbenicillin resistant. That is, these microbes have developed resistance mechanisms to these antibiotics.

Table 2. Diameter of the zones of growth retardation of microorganisms under the influence of various antibiotics

\begin{tabular}{|c|c|c|c|c|c|}
\hline \multirow[t]{3}{*}{ Microorganism } & micrograms & & & & \\
\hline & $\begin{array}{l}\text { Streptomyci } \\
\mathrm{n},\end{array}$ & $\begin{array}{l}\text { Carbenicill } \\
\text { in, }\end{array}$ & $\begin{array}{l}\text { Doxycyclin } \\
\text { e, }\end{array}$ & $\begin{array}{l}\text { Amoxicilli } \\
\mathrm{n} 20\end{array}$ & $\begin{array}{l}\text { Tetracycli } \\
\text { ne, }\end{array}$ \\
\hline & 30 & 100 & 30 & & 30 \\
\hline $\begin{array}{l}\text { Lactic } \text { acid } \\
\text { (mixture } 1 \text { ) }\end{array}$ & $30,0 \pm 0,40$ & $23,0 \pm 0,10$ & $26,0 \pm 0,62$ & $8,0 \pm 0,20$ & $28,0 \pm 0,20$ \\
\hline $\begin{array}{l}\text { Lactic acid bacteria } \\
\text { (mixture 2) }\end{array}$ & $35,0 \pm 0,21$ & $14,0 \pm 0,09$ & $20,0 \pm 0,41$ & $10,0 \pm 0,40$ & $17,0 \pm 0,50$ \\
\hline Genus Bifidobacterium & $35,0 \pm 0,30$ & $10,0 \pm 0,20$ & $24,0 \pm 0,32$ & $12,0 \pm 0,50$ & $29,0 \pm 0,30$ \\
\hline Genus Lactobacillus & $30,0 \pm 0,12$ & $5,0 \pm 0,08$ & $28,0 \pm 0,40$ & $7,0 \pm 0,10$ & $30,0 \pm 0,20$ \\
\hline Genus Staphylococcus & $40,0 \pm 0,51$ & $5,0 \pm 0,20$ & $37,0 \pm 0,07$ & $4,0 \pm 0,07$ & $30,0 \pm 0,41$ \\
\hline Genus Streptococcus & $30,0 \pm 0,22$ & $15,0 \pm 0,08$ & $35,0 \pm 0,43$ & $5,0 \pm 0,09$ & $35,0 \pm 0,40$ \\
\hline Genus Escherichia & $40,0 \pm 0,42$ & $6,0 \pm 0,40$ & $32,0 \pm 0,32$ & $5,0 \pm 0,08$ & $28,0 \pm 0,24$ \\
\hline Genus Sarcina & $30,0 \pm 0,23$ & $6,0 \pm 0,20$ & $26,0 \pm 0,52$ & $5,0 \pm 0,20$ & $30,0 \pm 0,40$ \\
\hline Genus Bacillus & $40,0 \pm 0,31$ & $28,0 \pm 0,50$ & $30,0 \pm 0,41$ & $13,0 \pm 0,3$ & $35,0 \pm 0,51$ \\
\hline Genus Proteus & $38,0 \pm 0,20$ & $36,0 \pm 0,50$ & $28,0 \pm 0,81$ & $14,0 \pm 0,40$ & $27,0 \pm 0,45$ \\
\hline Genus Bacteroides & $39,0 \pm 0,19$ & $34,0 \pm 0,42$ & $25,0 \pm 0,10$ & $10,0 \pm 0,12$ & $26,0 \pm 0,30$ \\
\hline
\end{tabular}

Amoxicillin is a semi-synthetic broad-spectrum penicillin antibiotic. Carbenicillin is a semisynthetic penicillin antibiotic with a broad spectrum of activity. It acts as a bactericide by inhibiting the bacterial cell wall production.

Beta-lactam antibiotics (also known as beta-lactams) are a class of antibiotics that share a beta-lactam ring in their structure. Penicillins, cephalosporins, carbapenems, and monobactams are all beta-lactam antibiotics. The identical chemical structure of all beta-lactams results in the same mechanism of action (inhibition of bacterial cell wall formation), as well as cross-allergy in some patients.
Penicillins, cephalosporins, and monobactams are all susceptible to hydrolysis by special enzymes called beta-lactamases, which are produced by a variety of bacteria. Carbapenems exhibit much greater resistance to beta-lactamases than other antibiotics.

Given their excellent clinical performance and minimal toxicity, beta-lactam antibiotics are the cornerstone of antimicrobial chemotherapy at the moment, occupying a prominent position in the treatment of the majority of illnesses.

Beta-lactamases are found in a wide variety of Gram-negative bacteria and are also produced by a number of Gram-positive bacteria (staphylococci). There are around 200 different types of enzymes recognized to date. Recently, it was discovered that up to $90 \%$ of resistant bacterial strains obtained in clinical settings are capable of generating betalactamases, which confers resistance.

Beta-lactam antibiotics' efficiency may be reduced as a result of the evolution of resistance, the most common mechanism of which is the creation of beta-lactamases by bacteria.

The development of new beta-lactam antibiotics and their implementation into practice for the treatment of infectious diseases caused by strains resistant to known antibiotics has resulted in an increasingly small time interval between the use of a new medicine and the emergence of resistance to it. Figure 3. Illustrates the sensitivity/resistance of the major representatives of the oral microbiota to antibiotics administered at various concentrations to the discs.

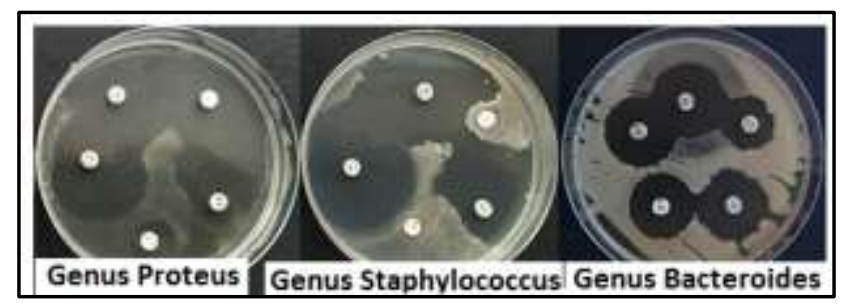

Figure 3: Examples of the sensitivity/resistance of the main representatives of the oral microflora to antibiotic preparations applied to the discs in a certain concentration

Antibiotic resistance prevention methods that are most successful should be directed at microbial populations in general. Antibiotic resistance has spread globally in recent years as a result of the selection pressure exerted by antibiotics used in medical treatment.

\section{Conclusions}

The objectives of this study were to examine the immunological parameters (total IgA and secretory IgA concentrations) in the oral fluid of examined 
individuals under normal and pathological conditions; and to determine the sensitivity/resistance of microorganisms - the primary representatives of the oral microflora-to antimicrobial drugs widely used in modern therapeutic practice (antibiotics) in vitro. To accomplish the study's aims, 65 individuals ranging in age from 18 to 50 years were evaluated. Microorganisms were quantified quantitatively by counting colonies (CFU) on the agar medium's surface and then translating to a particular unit of the oral cavity's area $(4 \mathrm{~cm} 2)$. The analytical findings were obtained using photometric measurements at a wavelength of $450 \mathrm{~nm}$. The test material is blood serum. For analysis, 100L of material is required.

The results of this study revealed that the amount of total IgA in oral fluid is considerably lower in persons with dental and periodontal disorders than in healthy individuals. This reflects a reduction in the oral cavity's particular resistance and the activation of carious / periodontal processes. Individuals with $\lg$ A deficiency have been reported to have an increased risk of developing caries and/or periodontal disease.

However, the results indicated that the oral cavity microbiota in the comparative groups was dominated by staphylococci and streptococci. There were discovered Enterobacteria, Veillonella, bacteroides, actinomycetes, and Neisseria. Streptococci representatives were the most often seeded - accounting for $57 \%$ of all microorganisms sown in this biotope. Staphylococcus representatives accounted for $22 \%$, enterobacteria accounted for up to $15 \%$, and Neisseria accounted for around $4 \%$ and $2 \%$, respectively. There was a decrease in the colonization of the cavity by members of the normal microflora Neisseria lactamica, Clostridium sphenoides, and Clostridium ramosum, as well as an increase in the frequency of opportunistic microorganisms Enterococcus faecium and Streptococcus parvulus in the representatives of the older group 2.

Finally, the results indicated that a drop in $\operatorname{sIgA}$ levels in periodontal disease patients' saliva suggests a loss of local mucous membrane protection, therefore increasing the risk of caries and periodontal disease development. The decreased sIgA level in the oral cavity generates circumstances in which tooth tissue is more vulnerable to cariescausing microbe adhesion than in healthy individuals.

\section{Author Statements:}

- The authors declare that they have equal right on this paper.
- The authors declare that they have no known competing financial interests or personal relationships that could have appeared to influence the work reported in this paper

- The authors declare that they have nobody or nocompany to acknowledge.

\section{References}

[1] Mestecky, J., McGhee, J. R., Michalek, S. M., Arnold, R. R., Crago, S. S., \& Babb, J. L. (1978). Concept of the local and common mucosal immune response. In Secretory immunity and infection (pp. 185-192). Springer, Boston, MA.

[2] Mestecky, J. I. R. I., McGhee, J. R., Arnold, R. R., Michalek, S. M., Prince, S. J., \& Babb, J. L. (1978). Selective induction of an immune response in human external secretions by ingestion of bacterial antigen. The Journal of clinical investigation, 61(3), 731-737.

[3] Aps, J. K., \& Martens, L. C. (2005). The physiology of saliva and transfer of drugs into saliva. Forensic science international, 150(2-3), 119-131.

[4] Chiappin, S., Antonelli, G., Gatti, R., \& Elio, F. (2007). Saliva specimen: a new laboratory tool for diagnostic and basic investigation. Clinica chimica acta, 383(1-2), 30-40.

[5] Wu, Z., Lee, S., Abrams, W., Weissman, D., \& Malamud, D. (2006). The N-terminal SRCR-SID domain of gp-340 interacts with HIV type 1 gp120 sequences and inhibits viral infection. AIDS Research \& Human Retroviruses, 22(6), 508-515.

[6] Stoddard, E., Cannon, G., Ni, H., Karikó, K., Capodici, J., Malamud, D., \& Weissman, D. (2007). gp340 expressed on human genital epithelia binds HIV-1 envelope protein and facilitates viral transmission. The Journal of Immunology, 179(5), 3126-3132.

[7] Mandel, I. D. (1990). The diagnostic uses of saliva. Journal of Oral Pathology \& Medicine, 19(3), 119-125.

[8] Streckfus, C. F., \& Bigler, L. R. (2002). Saliva as a diagnostic fluid. Oral diseases, 8(2), 69-76.

[9] Nagler, R. M., Salameh, F., Reznick, A. Z., Livshits, V., \& Nahir, A. M. (2003). Salivary gland involvement in rheumatoid arthritis and its relationship to induced oxidative stress. Rheumatology, 42(10), 1234-1241.

[10] Humphrey, S. P., \& Williamson, R. T. (2001). A review of saliva: normal composition, flow, and function. The Journal of prosthetic dentistry, 85(2), 162-169.

[11] Saloom, H. F., \& Carpenter, G. H. (2018). Saliva and Gingival Crevicular Fluid: Contributions to Mucosal Defense. In Oral Mucosa in Health and Disease (pp. 91-103). Springer, Cham. 